\title{
The Architectural Object as a Sociospatial System
}

\author{
Lubomir Popov, Ph.D. ${ }^{1}$ \\ Franklin Goza, Ph.D. ${ }^{2}$ \\ ${ }^{1}$ Professor, School of Family and Consumer Sciences, American Culture Studies affiliated faculty, Bowling \\ Green State University \\ ${ }^{2}$ Associate Dean \& Professor of Sociology, College of Letters and Sciences, University of Wisconsin- \\ Whitewater
}

(C) 2017 Lubomir Popov,Franklin Goza

This is an open access article distributed under the Creative Commons Attribution-NonCommercial-NoDerivs license (http://creativecommons.org/licenses/by-nc-nd/3.0/)

DOI: 10.1515/eras-2017-0008

\begin{abstract}
Concerns with the social inadequacy of architecture and the movement towards user-centred design call for new perspectives and architectural visions that can help alleviate usability problems and make buildings more user-friendly and accommodating in supporting user operations. Accordingly, this study proposes the concept of the sociospatial system. This conceptualization is based on premises of the systems approach and a social science interpretation of the problem. We provide a foundation for relating spatial-material objects and sociocultural phenomena, for homogenizing different discipline perspectives, and for developing relational descriptions of the systems components. This allows the built environment to be represented in terms of the sociocultural organism that it accommodates. The elastic concept of the sociospatial system described herein can be used as a holistic framework for the study of sociospatial interactions; including facilities programming and design, where this way of thinking can facilitate a holistic interpretation of a wide array of considerations.
\end{abstract}

Keywords: Environmental Design, Philosophy, Environmental Design Theory, Sociospatial System, Systems Approach in Architecture, Sociocultural Aspects of Architecture, User Needs Research, Usability in Architecture, User-Centered Architectural Design, Facilities Programming, Architectural Programming, Facilities Planning Philosophy

\section{INTRODUCTION}

In recent decades there has been a great deal of debate about the social inadequacy of architecture (Boudon, 1972; Brolin, 1976; Jacobs, 1961; Huxtable, 1970). These discussions come from the left and the right, from users, intellectuals, and aesthetes alike and are no longer conversations simply about style, as these appraisals have transcended the boundaries of pure aesthetics. Instead, the major concern now raised typically addresses the low functional performance of buildings in rapidly changing work and everyday settings. Reactions to the usability of built environment range from disappointment to frustration. These reactions indicate major disturbances in the patterns of the social reproduction of built environment. These issues may be due to a number of factors, ranging from inadequate practices within the architectural profession to rapidly evolving social circumstances.

A large body of literature spanning several decades documents the failures of modern architecture. Beginning in the 1960s, Jane Jacobs (1961), James Bailey (1965), Ada Louise Huxtable (1970), and Brent Brolin (1976) all demonstrated that the major problem with the inadequate social functioning of contemporary buildings comes from adherence to dominant architectural conceptualizations, beliefs, and values. A second generation of architectural researchers and critics goes even further, dissecting architects' attitudes, documenting their patronizing and patriarchal arrogance, and exposing their disregard for users' actual needs and values (Franck and Lepori, 2007). 
When dominant views and mind sets seem to be ineffective in producing wellfunctioning architecture, a simple strategy often employed has been to search for a new conceptual apparatus. An important meta-theoretical procedure often used for developing new conceptualizations is to employ a wider interpretation of the object of study. Such an approach presupposes expanding the conceptual boundaries of the architectural object in order to create a new way of looking at it, interpreting it, and conceptualizing it (Balint and Shelton, 1996; Gelatt, 1989; Roth, 1999).

As in other disciplines, architectural thinking is based on precedents and prototypes. These prototypes integrate all design concerns into one syncretic whole, including considerations about material, form, structure, aesthetic appearance, and manufacturing processes (Jones, 1992). Over the course of decades, these prototypes have naturally emerged through trial and error. It is a slow but sure evolutionary process that prevents major errors and disappointments. For a long time, the syncretic nature of the prototypes ensured congruence among all aspects in the process of artefication.

However, the last one hundred years have been marked by revolutions in both the social and technical arenas. The sociocultural organism began changing so quickly that the evolutionary methods of adjusting simply could not catch up. Therefore, the slow evolutionary path to development suddenly ceased to work. The rapid disruption of the prototype unexpectedly created a gap that the architectural community did not even realize. The syncretic interrelations between users and artefacts that had been tacitly integrated into the prototype were lost, and there have been no new mechanisms to restore these relationships. Some new buildings have been rejected by society, while others were deemed highly inconvenient and uncomfortable. This problematic situation has been identified and explicated since at least the 1960s (Boudon, 1972; Brolin, 1976; Jacobs, 1961; Huxtable, 1970), with little or no satisfactory response from the architectural community, the scholarly community, or society as a whole.

This condensed analysis of this issue illustrates that the roots of the problem emerge with the failure of prototype thinking in this new era of rapid social and technological changes. One conclusion is that there is a need to restore the relationship between users and the social functional environment of the artefact. This need is interpreted herein as a research problem. Specifically, how to develop a conceptualization that will fulfil the role of the prototype in the new sociocultural situation? Such a conceptualization should provide an integrative framework for the major components that have broken away since the failure of the prototype.

There are many components that comprise the relationships between the artefact and its environment, and these relationships can be discussed at multiple levels of detail. However, space limitations prevent us from doing all this in a single article. For that reason, the scope of this study is limited to the development of a new way of thinking that will allow for the integration of the social functional environment into the study of the architectural artefact. Therefore, the goal of this treatise is to propose a broad conceptual framework that will integrate spatial-material and sociocultural objects and phenomena into one holistic entity that will restore the missing connections between the spatial-material morphology of the artefact and its users. The purpose of this conceptual product is to guide the study of building users in facilities programming, post-occupancy evaluation, and policy making.

In order to achieve this goal, we propose the concept of the sociospatial system. This concept lays the groundwork for relating spatial-material (architectural) objects and social phenomena and delineates the wholeness within which the interactions between the spatial and the social take place, as well as the ensuing sociospatial relationships. This conceptualization represents more of a guiding instrument than a theoretical model and may 
assist with the analysis of the mutual redefinition of the spatial and the social. Depending on researchers' objectives, the concept of the sociospatial system may also be used as a foundation for the study of sociospatial interactions or as a holistic and integrative framework for organizing information.

\section{METATHEORETICAL CONSIDERATIONS}

The conceptualisation of the architectural object as a sociospatial system is based on the assumption that spatial-material configurations acquire architectural qualities in the social environment. This leads to an emphasis on the relationship between building structures and their social functional environment. It accentuates the importance of the social aspect and brings it to the conceptualisation of architecture. This way of thinking leads to augmenting and broadening the concept of the architectural object and incorporating social components into it. Such a conceptualisation of architecture largely determines how this project's subject matter is viewed, approached, and construed.

The theoretical strategy we use here is based on considerations regarding the problem, the goal, and underlying assumptions. Our objective is to create an overarching concept that will integrate spatial and sociocultural aspects as it considers multiple systems and sociocultural approaches. The sociocultural approach introduces social science rationality and emphasises the social nature of reality. Further, this approach interprets the architectural object as being interconnected with the social organism that is housed(or accommodated) by that architectural object.

The systems approach (Bailey, 1994, 2001; Banathy, 1996; Bausch, 2001; Hubka, 1988; Jackson, 2002; Luhmann, 1995, 2000, 2012) emphasises the understanding that the world is complex and interconnected. Systems thinking, in conjunction with the sociological imagination, provides a platform for considering a multitude of aspects, circumstances, constraints, and opportunities. When dealing with the pragmatic aspects of function, a systemic mode of study has multiple advantages: it provides an integrative platform for a number of disciplinary projections (Gero and Kannengiesser, 2004; Nadler, 1981), and it offers an area of mutual understanding for scholars from many social science disciplines, as well as to designers who share its rationality.

The conceptualisation we propose can be construed as a macro-model, or external model, of architecture because it attempts to incorporate, into one holistic entity, architectural and social components. This notion expands the boundaries of the object of architecture and architectural design with the belief that such a cognitive platform will bring a new perspective to the formulation of problems and solutions in design research.

The current level of abstraction is influenced by particular epistemological beliefs which postulate that new conceptualisations should start with developing a foundation at the philosophical level and then should proceed through a cascade of concretisation and implementation. As such, the development of a practical instrument for data collection is not an objective at this phase of the project. The path from the development of new assumptions and ways of seeing the world to field research passes through multiple stages. It is a long process of operationalisation from philosophical premise to systemic model to disciplinary framework and then onto detailed research design and protocol. At each stage, it must be further developed, concretised, and evaluated. Each stage allows for scholars to come closer to a detailed framework or a practical instrument for field research and design. This ongoing endeavour is one that requires time, resources, and innovation.

At this juncture, our elaboration of the concept of the sociospatial system will be at the philosophical and theoretical levels of architecture, including a focus on facilities 
programming and user-centred design. Specially, it is meant to serve as a guiding platform for developing more concrete models and interface with developments in organisational theory, social sciences, and design that form the foundations for good facilities planning. Despite the abstract nature of the concept, field researchers and practicing architects can still benefit from its application. The challenges that this new vision presents will encourage such professionals to explore alternative ways of seeing existing problems, the role of the social sciences in architecture, and the benefits of increased collaboration with social researchers on projects requiring user studies. The following sections will further develop and elaborate this concept.

\section{THE SOCIOSPATIAL SYSTEM: AN OVERVIEW, SYSTEMIC PHENOMENA, AND BOUNDARIES}

The sociospatial system may be visualized as consisting of two subsystems, the sociocultural and the spatial-material. These two subsystems constantly interact and consequently develop multiple sets of interrelationships. These interactions occur in particular ways and maintain a certain level of congruence with each other. However, of the two, the sociocultural subsystem is the most active and powerful component of the sociospatial system. This strength enables the sociocultural subsystem to assimilate the spatial-material subsystem and thereby become a system generating component. In fact, the sociocultural subsystem actually creates the sociospatial system and "drives" its functioning. This act of assimilation and system generation enables us to view the sociospatial system as a particular type of social system (e.g. a school, hospital, or theatre). Alternatively, the concept of the sociospatial system may also be interpreted as a cross-section of the social system, one that reveals the social dimensions of the spatial-material subsystem (i.e. the architectural object as a material artefact, a building).

Although in reality the social and the architectural object coexist as one entity, they can be taken apart in the realm of scholarly abstractions, processed cognitively, and interactions and sociospatial relationships and structures conceptualised. The realm of interactions generates the specificity of the sociospatial system and the attributes that differentiate it from the social system. Within the realm of interactions, the sociocultural subsystem can be seen as a social organism that needs spatial accommodation, while the spatial-material subsystem becomes an architectural object that can provide such accommodation. The spatial-material object transforms into an architectural object as the result of its relationships with the social organism. The architectural phenomena acquire social qualities that depend on their purposeful relationships with social entities, phenomena, and activities. We will identify such interactions as social functional relationships. Accordingly, an architectural object (e.g. a school, hospital, or theatre) can only be conceptualised in relation to a particular social organism. In the vernacular, the same terms are routinely used to address both the building and the social organism that occupies said building.

The sociocultural subsystem and the processes taking place in it are complex, multilayered, and dynamic (Bailey, 1994; Banathy, 1996; Luman, 1995, 2012). These qualities influence the diversity of the mechanisms of interaction and the resultant relationships and structures. Because of this complexity, the sociospatial structure of the social system cannot be a monolithic entity, but rather it exists as a multitude of structures emerging in multiple levels of environmental interactions with the social organism. These sociospatial structures are defined by the characteristics of the social subsystem and, in particular, by the types of processes that serve as mechanisms of sociospatial interactions. The notion for this multistructural subsistence constitutes the foundation for conceptualising 
the interrelation of sociocultural processes and their spatial-material environment. This allows for the organisation of an overwhelming number of interactions and the introduction of cognitive order to representations of sociospatial interactions and structures (Banathy, 1996; Luman, 1995, 2012).

In different sociocultural situations, one spatial-material configuration will display different functional qualities and different degrees of adequacy. Building users with different sociocultural backgrounds will perceive the same spatial-material configuration in a very different way. For each user group the same architectural object will exhibit different attributes and qualities, to varying degrees, and with distinct intensities. For example, one excellent school building might be converted into a temporary relief shelter. As a shelter it would not function well. In case of natural catastrophe, the school building could also become a field hospital. However, the discomfort and operational problems would be tremendous.

Changes in the structure and the parameters of one component of the sociospatial system can lead to changes in many other components (Banathy, 1996). For instance, at the urban level, an economic crisis may lead to neighbourhood impoverishment and degradation. This can precipitate the deterioration of public services, a reduction of revenues in the retail and service sectors, a decrease in investments for maintaining buildings and spaces, and a gradual deterioration of the cityscape as a whole. Parallel to this deterioration, the crime rate increases, quality of education declines, and housing values plummet. More affluent citizens might start leaving these neighbourhoods in search of safer areas, better schools, and a better physical environment. The vacated housing units lose value and start attracting low-income people who now can afford to buy the lower-priced property in these areas. However, because the incomes and property values are generally lower, tax revenue is also reduced, leading to smaller local budgets and reductions in services and maintenance, as well as lower standards for maintaining public order. This cycle continues with a second exodus to other areas, followed by an influx of people with even lower incomes and a further deterioration of services and environments until the neighbourhood is finally transformed into a slum.

Similar scenarios occur with education. For example, changes in curriculum and teaching methods can make current schoolhouses obsolete and difficult to use. Consequently, a number of problems start emerging with the physical environment. New curriculum requires more specialised spaces and a different distribution of space types as many of the older spaces become obsolete, unsuitable, and difficult to use, thereby impeding the introduction of new teaching processes. For example, science students may start changing labs and workshop spaces very often. As a result, these students lose their sense of ownership. They also lose motivation to keep the common spaces organised and clean. When the school environment fails to function properly, students fail to see a need to be professional themselves and to behave responsibly. Cases of vandalism may increase dramatically. Similarly, traffic in the hallways may increase tremendously during breaks between classes and significantly increase the sense of overcrowding as the corridors and staircases cannot accommodate these large flows. Student altercations and harassment proliferate. The administration responds with tougher regulations. The school atmosphere is poisoned and learning outcomes plummet.

These scenarios illustrate the systemic nature of sociospatial entities and the interdependencies among the social processes and their physical environment. When the parameters of one component changes, so do the parameters of the many other components with which it interacts (Banathy, 1996). The components are subjected to particular influences and must restructure in order to maintain important properties of the system. These changes take place within certain limits influenced by the self-sustaining capabilities of the 
system. When the pressure to adapt exceeds the tolerance of the components, this leads to qualitative changes and to restructuring in the system.

However, not all changes in one component lead to transformations in other components of the same sociospatial system (Banathy, 1996). The limits of compatibility and consistency among the components establishes a relationship threshold. Below this threshold, parameters can change without changing the nature of a component. Each sociospatial system has its own inherent norm of compatibility among its subsystems, which shapes the identity of the system. When the components and the relationships among them change beyond the threshold of compatibility, the make-up of the sociospatial system changes and the system experiences major problems due to incompatibility.

For example, when a company experiences growth and hires new workers, there is pressure to build an addition or even a new, larger building. However, such plans do not emerge all at once. Initially, management tries to foster psychological and sociocultural mechanisms for coping with limited spatial resources. If this doesn't help, the next step is to engage in limited spatial restructuring. This intervention is confined to the reorganisation of furniture and to the addition of privacy screens. However, if the workforce is substantially increased, such reorganisation may be inadequate. If the density increases above certain limits, the social coping mechanisms no longer function. This might lead to major disruptions in the organisational structures and processes due to insufficient space. At this point, the growth needs to be accommodated with remodelling or a new building. Another scenario occurs when an organisation adopts new technologies and methods. If these changes are limited, the organisational subsystem can continue coexisting in the current building situation. However, more substantial technological and operational transformations in the organisation might require major restructuring of spatial resources.

Different ways of functioning activate and strain different structures and relationships between components. These structures and relationships might differ in intensity, importance, and stability (Banathy, 1996). The structures and the constituting relationships that are indispensable to the system are system-generating. Changes in the system-generating relationships and structures most directly impact the organisation and constitution of the system (Banathy, 1996). There are a number of secondary structures that can undergo substantial change within the current limits of the system without precipitating a major transformation of the system. For example, changes in organisational structures most directly involved in the goal-attainment strategy of an organisation quickly influence changes in the organisation's spatial structures. However, transformations in support activities may go on for a long time without any major modifications in the spatial structures. In such cases, adaptations can be implemented with managerial measures.

The conceptualisation of the sociospatial system as one entity leads to issues with its boundaries and its relationships with higher-level entities (Banathy, 1996). Boundaries of the sociospatial system are influenced by those of the sociocultural subsystem, the systemdefining component. The spatial component can be viewed as encircled by several concentric layers of the sociocultural subsystem. The layers are defined by the intensity of the connections inside them. The layers are also linked in an object-environment relationship. Each outer layer can be treated as an environment for an inner layer. Assuming these layers are nested, they can be peeled one by one like an onion. For example, a school exists in the environmental layer of its district, and the district itself exists within the city and finally the state department of education. Furthermore, all exist at the national level as part of its many institutions, agencies, and social entities.

The boundaries are constructed on the grounds of knowledge of the sociospatial phenomena, planning and design objectives, professional methodologies and practices, and 
other considerations. The expansion of the boundaries can have a positive effect on considering all important social environment influences on the architecture object (Banathy, 1996). This can also lead to improving the social adequacy of the architectural object. However, for this to occur, much more research is required, and it will likely result in a dramatic increase in the volume of information, as well as the complexities related to design decision-making.

While every sociospatial system can be viewed as a component of a larger sociospatial entity, its components can also be treated as lower level systems, or subsystems (Banathy, 1996; Luman, 1995). In this conceptualisation, each subsystem consists of still smaller components that, in turn, can be viewed as sub-subsystems that in turn consist of their own sub-sub-subsystems. For example, a school is a system composed of subsystems of a smaller scale: classrooms, labs, lecture halls, libraries, workshops, gyms, cafeterias, and so forth. Further, if we look at any one of these subsystems (e.g. the gym), we will see that it, too, holds dozens of possible different functional areas that may also be considered as subsubsystems.

\section{THE SOCIOSPATIAL STRUCTURES: RELATIONS, RELATIONAL REPRESENTATIONS, AND DESCRIPTIONS}

The study of a multilayered sociospatial system should begin with an analysis of the entire entity, and then, spiralling from its whole, to the analysis of its components, and to the connections between them (Banathy, 1996; Luman, 2012). The purpose of such analysis is not to learn everything about each component, but rather to discover common interaction points and structures and find the relevant facets, corresponding interactions, and ensuing relationships between them.

One way to analyse a system without violating the principle of holism, which is one of the major systems principles(Banathy, 1996; Bohm, 1980/2002; Hubka, 1988), is to identify analytical "cross-sections" that involve all relevant components. Another major requirement of the systems approach is that the system's components be defined in relation to each other and the whole (Banathy, 1996; Hubka, 1988; Luhmann, 2012). To do this, we need to understand and map the structures rather than the materiality or the morphology of the system. From this vantage point, the research focus shifts from morphology and substance to relationships and structures, requiring an investigation of the relationships among the components and within the entire system. Instead of focusing on the components themselves, the research process should focus on the interactions among components with the goal to understand and describe each one of them through their relationships with the other components. Each of the components contributes to the delineation of the functional niche of the other (Banathy, 1996). From this point of view, the spatial subsystem and its components can be understood only in relation to the sociospatial subsystem and vice versa.

Structures are networks of relationships and functional niches (Banathy, 1996), a point elaborated below. The analysis of structures presupposes interrelatedness and references in relational terms. When a structure is represented in relational terms, it sustains its autonomous existence as a conceptual entity with a wholeness that can be grasped intellectually. Furthermore, components of the sociospatial system are projected on that structural cross-section of the system and represented only by the facets that are relevant to the structure. These in effect are snapshots of the components "taken" in respect to the structure that is under consideration. The relational nature of this perspective is implemented by pinpointing specific cross-sections, projection planes, aspects, or snapshots that encompass the points of interaction and arranging them into structures. After the identification of the 
components and the mechanisms of interaction, the relational images can be further developed in terms of content and morphological distinctiveness.

According to this perspective, the sociospatial system is understood in terms of relationships and structures (Banathy, 1996). The components are represented by their relationships and functional niches. In this way, each component is inseparable from the others. The ensuing structures are heterogenic, including relational projections of both spatial and sociocultural components. Those components are represented by particular aspects or facets that are relevant to the type of structure. The aspects that are taken into consideration might not be the most important aspects of the phenomena, but they are relevant to sustaining the wholeness of the sociospatial system (Banathy, 1996).

\section{A COMPLEMENTARY VIEW: FUNCTIONS AS RELATIONAL REPRESENTATIONS}

Relationships in systems can be viewed either through the lens of structure or the lens of function. These two options roughly correspond to the systemic-structural and systemicfunctional versions of the systems approach (Bedny and Karwowski, 2007; Eggins, 2005). In the previous section, we discussed sociospatial structures and structural descriptions as networks of relationships. With this approach, the emphasis is on the network of relationships that provides the integrity and wholeness of the object/system. As such, this is a macroscale approach, looking at the whole, and emphasizing the systemic nature of the object. However, we also need this complementary approach to describe individual system components in relational terms and to present these components as nodes of relationships with other components of the system. This approach is consistent with the realm of systemic-functional reasoning where function is a relational and emergent phenomenon and the object of analysis is constructed by studying its relationships with other objects (Bedny and Karwowski, 2007; Eggins, 2005; Hubka 1988). This is especially important when we want to focus on a single systemic component, describe it, and analyze it in relational terms.

From a systemic-functional perspective, the system can be represented by its functional niches and their morphological/material infill(Bedny and Karwowski, 2007; Eggins, 2005). The functional niche is an immaterial node or hub of relationships, offering an "empty shell" that can be filled with appropriate morphology. The niche of a component is assembled from relationships between that component and other components that constitute its environment. Each functional niche is produced by, and represents, the environment of its infill. In other words, each niche is formed by abstracting specific aspects of the components that constitute its environment. From this perspective, the near environment of a component can be represented interchangeably by the niche it delineates.

For example, the functional niche of the cafeteria of an elementary school is produced by its connections to other school components, including the classroom component, the school commons or public assembly component, the library, the gym, and other components. The cafeteria as a component of the school system is shaped by its own nature of a food service outlet and the culture and behavioural patterns of students, teachers, and staff. In addition, it is shaped by its relationships with other school components that comprise its environment. All of these factors and components ultimately generate a node or relationships that comprise the functional niche of the cafeteria within the school system. The functional description of the cafeteria is the niche, while the actual cafeteria organisation created to serve that school will be the infill of the cafeteria niche.

When functional niches are construed in terms of nodes/hubs of relationships, they can be treated as constitutive elements of the sociospatial structures. The sociospatial system can 
then be described in terms of niches and relationships (or functions). These relational descriptions provide information about particular aspects of the sociocultural subsystem on the one hand and the spatial-material morphology of the infill of the niches on the other. Both of these relational descriptions can be treated as descriptions of the two polar points of the sociospatial axis. The description of the sociocultural environment in terms of its desired spatial support provides information about the necessary qualities of the architectural morphology. The description of the spatial morphology in social functional terms is based on particular interpretations of the sociocultural environment. One such description is in terms of the necessary condition of the sociocultural organism. This duality is possible because of the mutual determination of the components of the sociospatial system.

From this point of view, the architectural object is represented by its functional niche, which in turn is a hub or a node of the relationships within the sociocultural subsystem. The relationships of an object with its environment constitute a particular class of properties for this object. In this case, these are the architectural qualities of the object's spatial-material structures. These architectural qualities are engendered and conditioned by the social components of the sociospatial system. When these qualities are interpreted in functional terms, they are referred to as the social functions of the architectural object.

The functional niche is a concept that relates and connects the building to sociocultural phenomena. This concept fulfils the requirement for a holistic analysis of the sociospatial system and the production of knowledge for design decision-making. This conceptualisation allows the substitution of the functional description of the architectural object for the sociocultural subsystem as the functional description carries within itself a special projection of selected parameters of the sociocultural organism.

This is important for design practice because it allows researchers to present the most relevant information for design decision-making, and eliminates the information overload created by the immense complexity of the sociocultural subsystem. The sociocultural organism has countless dimensions, and describing each one of them leads to the accumulation of tremendous quantities of information. By focusing on specific aspects, architects mitigate the information overload that designers experience. This facilitates the understanding of information, and provides the most important information for decisionmaking. Thus, an information domain is produced that includes the sociocultural subsystem (or environment), the system of functions (sociospatial structures or functional niches), and the architectural object as a means for procuring these functions.

When the concept of functional niche has to be operationalised, a subsequent problem will emerge, operationalising the concept of functional environment as it delineates the ontological basis for developing the system of functions. The concept of functional environment requires further development as an ontological matrix or framework (Banathy, 1996; Bedny and Karwowski, 2007). Juxtaposing this with social reality will highlight the facets that are relevant to design decision-making. The role of this matrix is to guide and organise the research procedures regarding the sociocultural organism and especially designrelated aspects (Banathy, 1996). With the help of such a matrix, the social reality is construed in a new way that involves only the aspects and relationships pertinent to sociospatial interactions. This matrix offers cognitive templates that facilitate the collection and organisation of information in accord with the procedural requirements of the design process and the proficiency of designers to use such information.

The concept of (sociocultural) functional environment delineates the major object of study in sociospatial research because of the system-producing role of the sociocultural subsystem for the sociospatial system. The concept of (sociocultural) functional environment narrows the research area to particular sociocultural phenomena. It also provides a 
"projection" plane on which we can "visualise" the relevant aspects and facets of the various sociocultural phenomena. In this way, the concept of functional environment guides the research effort toward the relevant ontological layers of the investigation process. The concept of functional environment provides a vantage point for construing sociospatial relationships. These types of systems emphasise the interrelationships and the definition of each component in terms of the other components.

\section{RELATIONAL REPRESENTATIONS AS INTEGRATIVE MECHANISMS AND BRIDGES TO THE SOCIAL SCIENCES}

The conceptual apparatus developed here is a systems interpretation of the functionalist worldview. It facilitates the creation of a model of the social functioning of the architectural object that transcends functionalism and allows functionalist thinking to be integrated within the holistic framework of the systems approach. Because systems thinking delineates a broader field of vision, it creates more possibilities for efficient definition of, and control over, the role of each research aspect and procedure (Banathy, 1996, Luman, 2012). Sociospatial relationships can be viewed not only in terms of functions, but also in other terms that complement functional descriptions. For example, systems thinking allows consideration not only of relationships, but also of social morphology components such as social organisation, activities, and needs (Bailey, 1994; Banathy, 1996; Luman, 1995).

Systemic-functional views call attention to mutual influence, definition, and description of one component in terms of others(Bedny and Karwowski, 2007; Eggins, 2005). The systemic-functional approach is instrumental in defining the functional environment, functional relationships and niches, and their organisation into structures. The systemicfunctional perspective focuses the research effort on the sociocultural reality as a major source of defining the attributes of the architectural object. This perspective also presupposes interconnectivity of the components, a framework or medium for interrelating them, and a relational approach to definition.

Because of the high level of abstraction, it is very difficult to operationalise these general guidelines at the disciplinary level(Bausch, 2001; Banathy, 1996; Bedny and Karwowski, 2007). Moreover, the process of research translation and utilisation involves a number of levels of transition. The subsequent level of concretisation must adopt a different and more specific framework for relating components that will allow a transition from the identification of the social functional environment as an object of study to its examination as a particular social morphology with respect to its spatial aspects and design considerations(Bedny and Karwowski, 2007).

At the first stage of concretisation, functional relationships are interpreted as conditions that are necessary for the existence of the sociocultural subsystem (Bedny and Karwowski, 2007). This interpretation is possible because the notion of necessary conditions can be construed as an alternative way to represent relationships between a system's component and the whole system. However, the representation of the conditions that support the sociocultural subsystem also describes the environment of this sociocultural subsystem. Thus, the description of the sociocultural subsystem in terms of its necessary conditions is a way to determine the attributes and the performance specifications of the corresponding spatial subsystem and, in particular, the architectural object. This description of the architectural object from a sociocultural perspective presents the sociocultural aspects of the spatial morphology. Such a vantage point allows the spatial ontology to be interpreted as a sociocultural one. In this way, it is construed as a component of sociocultural processes.

The representation of the architectural object in terms of its social functions and the 
description of the sociocultural organism in terms of necessary conditions are mutually interchangeable interpretations of identical relationships and structures viewed from different perspectives. Depending on the vantage point, they can alternatively represent the sociocultural subsystem or the spatial-morphological subsystem. The functional representation emphasises the architectural object as a functional constellation and the instrument for supporting the sociocultural organism. When the concept of necessary condition is used as a vantage point, the research focus moves to the sociocultural subsystem.

At the second stage of concretisation, the concept of necessary conditions is translated into social science terms. The necessary conditions are interpreted as needs(Bedny and Karwowski, 2007). The concept of needs can be construed as a relationship between a social entity and its environment - in this case, the sociocultural subsystem and its environment. From such a perspective, the notion of the necessary conditions can be operationalised further by using the concept of need and researching the social entity regarding these needs(Bedny and Karwowski, 2007).

At the third stage of operationalisation, researchers have to explore corresponding social science theories and methodologies. These will have completely different content than the general systems conceptualisations (Bailey, 1994; Banathy, 1996; Bedny and Karwowski, 2007). There are a number of theories about human needs, their emergence, and their management. These theories make different references to the study of other social phenomena, like activities, cultural patterns, and preferences (Bedny and Karwowski, 2007). The development of a theory of needs regarding the sociospatial system is a forthcoming challenge for the community of environment and behaviour researchers, as well as for mainstream social scientists. However, the concept of the sociospatial system presented herein will guide researchers in the realm of social science theories and methods.

This approach allows the sociocultural subsystem to be analysed within a holistic frame of reference and its sociospatial attributes to be conceptualised. The cycle can be repeated several times, and each time the outcomes will become more concrete and specific. The wholeness is construed in terms of sociospatial structures that are constituted by relational attributes of morphological components. These qualities are of primary interest in the process of programming the sociospatial system and its interactions. The remaining attributes of the sociocultural organism are researched to create a cognitive background to the extent necessary for reconstructing the sociospatial structures. By focusing on relevant components and specific aspects of study questions, these procedures offer the ability to manage and limit the research project in terms of effort and resources.

The concept of the sociospatial system defines the domain of interacting and interrelating, provides an integrative framework, and supports translations from several disciplinary languages. The systems representations of the object of study facilitate understanding of the whole, integration of components into a consolidated lattice structure, and a definition of the functional niche of each component. This is of prime importance when organising several aspects, facets, and ontological projections of the architectural object and its social functional environment. Such a concept can serve as a fundamental instrument for the researching, understanding, and programming of built environments.

\section{CONCLUDING REMARKS}

The concept of the sociospatial system offers a new way of conceptualising the existence and interaction of spatial-material morphology and the social organism that it accommodates. The concept provides a cognitive framework for homogenising a number of disparate disciplinary notions and conceptualisations of diverse phenomena. This cognitive 
framework allows for those diverse phenomena to be interrelated and to produce a new perspective. Such an understanding of the object of study leads to a broadening of the conceptual boundaries and the introduction of new perspectives, interpretations, and methodological principles. The broader notion of the social existence of the spatial phenomena leads to the discovery of new fundamental attributes and principles of congruence between the social and the spatial. From this position, the architectural object is influenced by its sociocultural functional environment. Therefore, in order to define the dimensions and attributes that the architectural object should possess, we have to research its social functional environment, which in effect is a study of the sociocultural organism accommodated by the building. From this vantage point, the study of the sociocultural subsystem is a prerequisite for the definition of the required parameters of the architectural object.

The concept of the sociospatial system offers guidance for conceptualising those objects studied by architectural programming. The sociocultural subsystem, viewed as a social functional environment of the spatial-material morphology, acquires the status of a focal object of study and becomes a major thematic area. The development of this area of interest presupposes scholarly engagement in the realm of the sociocultural phenomena and the adoption of social science methodological instruments. This approach delineates the thematic area of architectural programming and the scope of major research tasks in a new way.

The concept of the sociospatial system and the ensuing insights can be used as a guide for thinking theoretically about the social aspects of architecture, as well as for preparing research designs in facility programming and other kinds of sociospatial research. It will also help to better understand a number of functional issues that until now have been treated as pure spatial design problems that follow their own logic. Awareness of the social nature of architectural decision-making and the requisite social information will substantially change architectural practices, introducing more programmatic research and highlighting the need for more user research in architectural design.

\section{REFERENCES}

Bailey, J. (1965)'The case history of a failure',Architectural Forum Vol. 123, No. 12, pp.22-25.

Bailey, K.(1994)Sociology and the New Systems Theory, State University of New York Press, Albany, NY.

Bailey, K.(2001)'Systems theory', in J Turner (ed.), Handbook of Sociological Theory, Kluwer Academic/Plenum Publishers, New York, pp.379-401.

Balint, J.and Shelton, W. (1996)'Regaining the initiative: forging a new model of the patient-physician relationship. JAMA Vol. 275, No. 11, pp.887-891

Banathy, B. (1996)Designing Social Systems in a Changing World, Plenum Press, New York.

Bausch, K. (2001)TheEmerging Consensus in Social Systems Theory, Kluwer Academic/Plenum Publishers, New York.

Bedny, G.andKarwowski, W. (2007)ASystemic-Structural Theory of Activity: Applications to Human Performance and Work Design. CRC Press, Taylor \& Francis Group, Boca Raton, FL.

Bohm, D. (2002)Wholeness and the Implicate Order, Routledge, London, original work published 1980.

Boudon, P. (1972)Lived-in Architecture: Le Corbusier's Pessac Revisited, trans. G Onn, MIT Press, Cambridge: MA.

Brolin, B. (1976)TheFailure of Modern Architecture, Van Nostrand Reinhold, New York. 
Eggins, S. (2005)An Introduction to Systemic Functional Linguistics, 2nd ed, Bloomsbury Academic, London.

Franck, A.and Lepori, B. (2007)Architecture from the Inside out: From the Body, the Senses, the Site and the Community, 2nd ed, Wiley-Academy Press, Chichester, England; Hoboken.

Gelatt, H. (1989)'Positive uncertainty: a new decision-making framework for counseling',Journal of Counseling Psychology, Vol. 36, No. 2, pp.252-256.

Gero, J.and Kannengiesser, U. (2004)‘The situated function-behaviour-structure framework',Design Studies, Vol. 25, pp. 373-391.

Hubka, V. (1988)Theory of technical systems: a total concept theory for engineering design, Springer-Verlag, New York, NY.

Huxtable, A. (1970)Will they ever finish Bruckner Boulevard? Macmillan, New York, NY.

Jackson, M. (2002)Systems approaches to management, Kluwer Academic Publishers, Dordrecht, NL; New York.

Jacobs, J.(1961)The death and life of great American cities, Random House, New York.

Jones, J. C. (1992)Design methods,2nd edn, Van Nostrand Reinhold, New York.

Luhmann, N. (1995)Social systems, trans. J Bednarz, Stanford University Press, Stanford, CA.

Luhmann, N. (2000)Art as a social system,trans. E Knodt, Stanford University Press, Stanford, CA.

Luhmann, N. (2012)Introduction to systems theory,trans. PGilgen,Polity, Cambridge, England; Malden, MA.

Nadler, G. (1981)The planning and design approach, Wiley, New York.

Roth, S.(1999)'The state of design research’, Design Issues, Vol. 15, No. 2, pp. 18-26. 